3 McNeal JE, Redwine EA, Freiha FS, et al. Zonal distribution of prostatic adenocarcinoma. Correlation with histologic pattern and direction of spread. AmJ Surg Pathol 1988;12:897-906.

4 Barry M, Perner S, Demichelis F, et al. TMPRSS2-ERG fusion heterogeneity in multifocal prostate cancer: clinical and biologic implications. Urology 2007;70: 630-633.

5 Mehra R, Han B, Tomlins SA, et al. Heterogeneity of TMPRSS2 gene rearrangements in multifocal prostate adenocarcinoma: molecular evidence for an independent group of diseases. Cancer Res 2007;67: 7991-7995.

6 Darnel AD, Lafargue CJ, Vollmer RT, et al. TMPRSS2ERG fusion is frequently observed in gleason pattern 3 prostate cancer in a canadian cohort. Cancer Biol Ther 2009;8:125-130.

7 Demichelis F, Fall K, Perner S, et al. TMPRSS2:ERG gene fusion associated with lethal prostate cancer in a watchful waiting cohort. Oncogene 2007;26:4596-4599.

\title{
Response to Bismar and Trpkov
}

\author{
Modern Pathology (2010) 23, 1041-1042; doi:10.1038/modpathol.2010.90
}

To the Editor: We read with great interest the comments by Bismar and Trpkov ${ }^{1}$ in reference to our paper, 'Prostate cancer of transition zone origin lacks TMPRSS2-ERG gene fusion,' published in Modern Pathology. ${ }^{2}$

We agree that incidental prostate cancers of transition zone (TZ) origin in transurethral resection of the prostate (TURP) specimens usually have low Gleason scores and low tumor volumes. In contrast, a high proportion of the TZ tumor foci analyzed in our study had high Gleason scores and large volumes. However, as Bismar and Trpkov noted, prostate cancers detected incidentally in the course of TURP performed for benign prostatic disease can only be 'presumed' to be of TZ origin. Tumors of peripheral zone (PZ) origin may appear in TURP specimens either by inclusion of $\mathrm{PZ}$ tissue in the specimen or by extension of PZ tumor into the TZ. Moreover, the morphological features once thought to be almost exclusive to $\mathrm{TZ}$ tumors are also, though less frequently, observed in carcinomas of PZ origin. ${ }^{3}$ To ensure accurate zonal origin assignment and tumor volume determination in our study, we analyzed samples derived from mapped radical prostatectomy specimens. In our experience, tumor foci of both TZ and PZ origin are present in $\sim 52 \%$ of radical prostatectomy specimens, and the dominant focus is of $\mathrm{TZ}$ origin in $33 \%$ of cases. ${ }^{4}$ The samples in our study were selected to represent the spectrum of TZ tumors observed in radical prostatectomy specimens and, therefore, included tumors with a range of Gleason scores and tumor volumes. We included a few examples of low-grade, low-volume tumors, similar to those incidentally detected in TURP specimens, and also cases in which the TZ tumors had high Gleason scores and large volumes. Therefore, the TZ tumors in our study, derived from radical prostatectomy specimens, may not necessarily reflect the TZ tumors incidentally detected in TURP specimens.

To address the question of TMPRSS2-ERG gene fusion in tumors resembling those observed in
TURP specimens, we evaluated 10 additional radical prostatectomy specimens with $\mathrm{TZ}$ tumors of low volume and low grade. All 10 of these TZ tumors had a Gleason score of $6(3+3)$ and a mean volume of $0.36 \mathrm{~cm}^{3}$ (range, $0.02-0.86 \mathrm{~cm}^{3}$ ). No rearrangement of the $E R G$ gene was found in any of these 10 cases. We further evaluated five other radical prostatectomy specimens that contained multifocal prostate cancer, with seven tumor foci in the PZ and six foci in the TZ. The PZ tumor foci in these specimens had a mean Gleason score of 8 (range, 6-9) and a mean volume of $4.06 \mathrm{~cm}^{3}$ (range, $0.13-10.08 \mathrm{~cm}^{3}$ ), whereas the TZ tumor foci had a Gleason score of 6 (range, 6-7) and a mean volume of $0.38 \mathrm{~cm}^{3}$ (range, $0.01-2.16 \mathrm{~cm}^{3}$ ). Three of the seven PZ tumor foci showed rearrangement of the ERG gene, and in two of those three foci the rearrangement was associated with deletion of the $5^{\prime}$ end of the $E R G$ gene. Interestingly, one TZ tumor focus (Gleason score 6 and $0.07 \mathrm{~cm}^{3}$ ) also showed rearrangement of the ERG gene that was not associated with a deletion. Therefore, although the overwhelming majority of prostate cancers of TZ origin lack theTMPRSS2-ERG gene fusion, some $\mathrm{TZ}$ cancers $(1 / 46(2.17 \%)$ in our experience) carry this gene fusion, probably because of the biological heterogeneity of prostate cancer.

The conclusion that $\mathrm{TZ}$ tumors lack the TMPRSS2-ERG gene fusion was based on our observations in an admittedly limited study of 30 cases. $^{2}$ We acknowledged in the Discussion that large-scale independent studies were needed to further evaluate this finding. Prostate cancer, similar to most human diseases, varies significantly in its biological and clinical behaviors. It is not completely unexpected that rare cases of TZ tumors may carry the TMPRSS2-ERG gene fusion. Since the publication of our study, several other independent studies (reported in abstract form) have evaluated TMPRSS2$E R G$ gene fusion in tumors of TZ origin. ${ }^{5-7}$ Although a distinctively small number of such tumors expressed the TMPRSS2-ERG gene fusion, the 
overwhelming majority (78-94\%) of $\mathrm{TZ}$ tumors in these studies lacked the TMPRSS2-ERG gene fusion, thus confirming the zonal differences reported in our study.

Our study unfortunately was not designed to allow us to comment on the overall heterogeneity of TMPRSS2-ERG fusion among all of the tumor foci present in the specimens or among all of the foci of PZ or TZ origin. We evaluated only the largest focus in each zone and found discordance in TMPRSS2$E R G$ status between the foci in 13 of 30 cases $(43 \%)$. Only five cases had two TZ foci, and in all five cases, the second focus had Gleason scores that were either lower (two cases) or equivalent to (three cases) that of the studied tumor focus. Larger series focusing on specimens with more than one $\mathrm{TZ}$ tumor focus will be necessary to evaluate heterogeneity among the foci of TZ origin.

We also agree with Bizmar and Trpkov that establishing a proper cutoff level is critical to ensure reproducibility in fluorescence in situ hybridization (FISH) analyses. In our laboratory, the FISH slides were analyzed with an Axio Imager Z1 microscope (Carl Zeiss Microimaging, Jena, Germany) and a MetaSystems imaging system (Atlussheim, Germany), and a mean of 100 intact nuclei were analyzed $(100 \times$, oil immersion) in every case. Although cutoff levels in FISH analyses may vary for different probes and among different laboratories, we used the widely accepted definition of a proper cutoff as being the mean of false-positive findings in at least five negative control specimens plus three times the standard deviation. ${ }^{7-8}$ Hence, we analyzed $E R G$ rearrangement in normal prostate glands and established a cutoff level of $10 \%$ for our FISH analyses. In other words, if more than $90 \%$ of the evaluated nuclei in a TZ tumor focus showed no evidence of $E R G$ rearrangement, then that TZ focus was considered to lack the TMPRSS2-ERG gene fusion. It should be clarified here that in our study, most prostate cancers with the TMPRSS2-ERG gene fusion showed $E R G$ rearrangement in more than $80 \%$ of the evaluated nuclei.

In summary, we agree with Bismar and Trpkov that, although the overwhelming majority of prostate tumors of TZ lack the TMPRSS2-ERG gene fusion, a small subset of them may still carry this gene fusion. Since the publication of our series, other investigators have confirmed that the incidence of TMPRSS2-ERG gene fusion in TZ tumors is significantly lower than that in PZ tumors, suggesting that biological and genetic differences exist in prostate cancer of different zonal origins. The type of specimens used, the criteria applied to assign zonal origin and technical differences among the reported studies may have also contributed to the observed differences in the incidence of this gene fusion. We thank Bismar and Trpkov for their comments and for the opportunity to clarify the issues they raised.

\section{Disclosure/conflict of interest}

The authors declare no conflict of interest.

Charles C Guo, Patricia Troncoso, Yan Wang, Li Xiao and Bogdan A Czerniak Department of Pathology, The University of Texas M.D. Anderson Cancer Center, Houston, TX, USA E-mail: bczernia@mdanderson.org

\section{References}

1 Bismar TA, Trpkov K. TMPRSS2-ERG gene fusion in transition zone prostate cancer. Mod Pathol 2010; 23:1040-1041

2 Guo CC, Zuo G, Cao D, et al. Prostate cancer of transition zone origin lacks TMPRSS2-ERG gene fusion. Mod Pathol 2009;22:866-871.

3 Garcia JJ, Al-Ahmadie HA, Gopalan A, et al. Do prostatic transition zone tumors have a distinct morphology? Am J Surg Pathol 2008;32:1709-1714.

4 Chen ME, Johnston DA, Tang K, et al. Detailed mapping of prostate carcinoma foci: biopsy strategy implications. Cancer 2000;89:1800-1809.

5 Gopalan A, Savage C, Maschino A, et al. TMPRSS2-ERG rearrangement in transition zone (TZ) versus anterior peripheral zone (PZ) prostate cancer: relative incidence and correlation with 'TZ-look' histology. Mod Pathol 2010;23(Suppl 1):193A.

6 Braun M, Scheble VJ, Wilbertz T, et al. Cohort design and localization is critical for the understanding of the clinical implications of prostate cancer with ERG rearrangement. Mod Pathol 2010;23(Suppl 1):181A.

7 Falzarano SM, Navas M, Simmerman K, et al. ERG rearrangement is present in a subset of transition zone prostatic tumors. Mod Pathol 2010;23(Suppl 1):191A.

8 Ventura RA, Martin-Subero JI, Jones M, et al. FISH analysis for the detection of lymphoma-associated chromosomal abnormalities in routine paraffinembedded tissue. J Mol Diagn 2006;8:141-151.

9 Lichter P, Bentz M, Joos S. Detection of chromosomal aberrations by means of molecular cytogenetics: painting of chromosomes and chromosomal subregions and comparative genomic hybridization. Methods Enzymol 1995;254:334-359. 